\title{
Annecy-le-Vieux
}

Sommet du Mont-Rampon

\section{Loïc Serrières}

\section{(2) OpenEdition}

Édition électronique

URL : http://journals.openedition.org/adlfi/7085

ISSN : 2114-0502

Éditeur

Ministère de la culture

Référence électronique

Loïc Serrières, «Annecy-le-Vieux », ADLFI. Archéologie de la France - Informations [En ligne], RhôneAlpes, mis en ligne le 01 mars 2007, consulté le 03 mai 2019. URL : http://journals.openedition.org/ adlfi/7085

Ce document a été généré automatiquement le 3 mai 2019.

(c) Ministère de la Culture et de la Communication, CNRS 


\title{
Annecy-le-Vieux
}

\author{
Sommet du Mont-Rampon
}

\section{Loïc Serrières}

Identifiant de l'opération archéologique : 229493

Date de l'opération : 2007 (SU)

1 Connu depuis le milieu des années 1980, le sommet du Mont-Rampon est resté inédit afin d'éviter son pillage par les adeptes de la télédétection. Dans le cadre d'une prospection thématique (Les sites fortifiés de hauteur de l'âge du Fer dans les Alpes du Nord) ce site fut l'objet de ramassages, d'un relevé photographique, d'un relevé GPS des deux enceintes et d'un nouvel examen du matériel recueilli antérieurement. L'imminence de travaux d'aménagement a motivé la réalisation d'une opération de sauvetage urgent afin de sonder l'emplacement où la poursuite des travaux devait croiser le mur ouest.

2 À cet emplacement, le tracé de l'enceinte a été repéré. Celle-ci n'était pas fondée et l'opération n'a pas pu renseigner le mode de construction. L'absence de stratigraphie en avant comme en arrière du tracé n'a pas permis de proposer une datation. Globalement, le sondage a confirmé les données recueillies en prospection. Le sommet du MontRampon a fait l'objet de quatre occupations :

3 Le rempart de pierres sèches intègre un corpus de treize sites du même type en HauteSavoie. La reprise du dossier des oppida de Haute-Savoie semble en fait suggérer une édification des fortifications à la période gallo-romaine. L'occupation de hauteur est un phénomène important, à réévaluer et à intégrer à d'autres données :

Le sommet du Mont-Rampon appartient à cet ensemble et sa fortification telle qu'elle apparaît actuellement doit être rattachée au Bas-Empire. Pour autant, les prospections et le sondage ont su montrer que le site n'était pas vierge alors. L'occupation fortifiée de hauteur gallo-romaine prend place sur des sites souvent déjà occupés à des périodes antérieures. Malheureusement, ces occupations antérieures sont, de fait, difficiles à percevoir et ne peuvent être qualifiées. 
INDEX

operation sauvetage urgent (SU)

Index géographique : Rhône-Alpes, Haute-Savoie, Annecy-le-Vieux

Index chronologique : Bas-Empire, Âge du Bronze, Âge du Fer, Néolithique

\section{AUTEURS}

LOÏC SERRIÈRES 